\title{
Penambahan Bekatul dan Angkak pada Produk Agar-agar sebagai Alternatif Cemilan Pengikat Kolesterol
}

\section{Jelly Product with Rice Bran and Red Yeast Rice as an Alternative Food of Cholesterol Binder}

\author{
Hasim $^{1 *}$, Didah Nur Faridah ${ }^{2)}$, Ditha Mithania ${ }^{2)}$ \\ ${ }^{1)}$ Departemen Biokimia, Fakultas Matematika dan Ilmu Pengetahuan Alam, Institut Pertanian Bogor, Bogor \\ ${ }^{2)}$ Departemen Ilmu dan Teknologi Pangan, Fakultas Teknologi Pertanian, Institut Pertanian Bogor, Bogor
}

\begin{abstract}
The prevalence of hypercholesterolemia in Indonesia reaches 11.2\%. Hypercholesterolemia can occur due to lack of exercise, consume too much food containing fat and cholesterol, and lack of fiber intake. Rice bran and red yeast rice contain fiber and phytochemical compounds that can reduce cholesterol, including alkaloids, saponins, tannins, flavonoids, and phenolics. The purpose of this study is to use rice bran and red yeast rice as an alternative snack that can potentially bind cholesterol. Rice bran and red yeast rice are added to agar to obtain gelatin snacks with high fiber content and phytochemical compounds. Agar is made into three formulas. Hedonic rating tests have been carried out, so that obtain the formula that is most preferred by consumers. The test results show that the formula with the addition of sodium citrate of $0.3 \%$ is most preferred, with the addition of bran and red yeast rice each of 30 and 0.8 grams and the use of agar for 7 grams. Gelatin products contain $14.80 \%$ food fiber and total flavonoids by $0.02 \%$. The total phenolic was not detected in agar products. The results of the cholesterol-binding test in vitro showed that gelatin products can bind cholesterol by $60.11 \%$.
\end{abstract}

Keywords: cholesterol, dietary fiber, phytochemicals, red yeast rice, rice bran

\begin{abstract}
Abstrak. Prevalensi hiperkolesterolemia di Indonesia mencapai 11.2\%. Hiperkolesterolemia dapat terjadi akibat kurangnya berolahraga, terlalu banyak mengonsumsi makanan mengandung lemak dan kolesterol, serta kurangnya asupan serat. Bekatul dan angkak memiliki kandungan serat dan senyawa fitokimia yang dapat menurunkan kolesterol, diantaranya yaitu alkaloid, saponin, tanin, flavonoid, dan fenolik. Tujuan penelitian ini adalah memanfaatkan bekatul dan angkak untuk dijadikan sebagai alternatif cemilan yang dapat berpotensi untuk mengikat kolesterol. Bekatul dan angkak ditambahkan pada agar-agar sehingga diperoleh cemilan agar-agar dengan kandungan serat yang tinggi dan mengandung senyawa fitokimia. Agar-agar dibuat menjadi tiga formula. Uji rating hedonik telah dilakukan sehingga diperoleh formula yang paling disukai oleh konsumen. Hasil uji menunjukkan bahwa formula dengan pemberian sodium sitrat sebesar $0.3 \%$ paling disukai, dengan penambahan bekatul dan angkak masing-masing sebesar 30 dan 0.8 gram dan penggunaan agar-agar sebesar 7 gram. Produk agar-agar mengandung serat pangan sebesar $14.80 \%$ dan total flavonoid sebesar $0.02 \%$. Total fenolik tidak terdeteksi pada produk agar-agar. Hasil uji pengikatan kolesterol secara in vitro menunjukkan bahwa produk agar-agar dapat mengikat kolesterol sebesar $60.11 \%$.
\end{abstract}

Kata Kunci: angkak, bekatul, fitokimia, kolesterol, serat pangan

Aplikasi Praktis: Penelitian ini memberikan informasi aplikasi angkak dan bekatul pada produk agar-
agar yang memiliki sifat fungsional yaitu dapat mengikat kolesterol. Produk agar-agar ini dapat
dikembangkan lebih lanjut menjadi pangan fungsional antihiperkolesterolemik.

\section{PENDAHULUAN}

Masalah kesehatan telah bergeser dari penyakit infeksi ke penyakit degeneratif. Perubahan gaya hidup seperti kurangnya berolahraga, konsumsi makanan mengandung lemak dan kolesterol yg berlebihan, serta kurangnya asupan serat dapat memicu penyakit degeneratif. Penyakit degeneratif yang cukup banyak memengaruhi angka kematian adalah penyakit kardiovaskular.

Hiperkolesterolemia dapat meningkatkan risiko penyakit kardiovaskular. Hiperkolesterolemia adalah suatu kondisi dengan kadar kolesterol darah melebihi 250
mg/dL (Mahan dan Escott-Stump 2008). Prevalensi hiperkolesterolemia di Indonesia pada rentang umur 2565 tahun menurut Riset Kesehatan Dasar (Riskesdas) 2013 adalah sebesar 1.5\% dan prevalensi batas tinggi (kadar kolesterol darah 200-249 mg/dL) adalah sebesar $11.2 \%$.

Upaya untuk menurunkan prevalensi hiperkolesterolemia dapat dilakukan dengan mengonsumsi pangan tinggi serat. Pangan dapat dikatakan sebagai pangan tinggi serat apabila kandungan serat minimal sebesar $6 \%$ (BPOM 2016). Pangan dengan komponen bioaktif juga dapat menurunkan kolesterol, diantaranya yaitu saponin,

Korespondensi: hasim@apps.ipb.ac.id 
alkaloid, tanin, dan flavonoid. Saponin memiliki karakteristik dapat mengikat kolesterol (Bottger dan Metzig 2013) dengan jalan menghambat penyerapan kolesterol pada usus dengan mengikat asam empedu dan mengganggu kolesterol misel (Ramirez-Jimenez et al. 2015). Flavonoid yang merupakan antioksidan dapat mencegah terjadinya peroksidasi lipid (Al-Numair et al. 2014), sedangkan tanin diketahui dapat memicu sekresi lemak sehingga penimbunan lemak dalam darah dapat dihindari (Dalimartha 2005).

Bekatul merupakan limbah penggilingan padi yang mengandung serat pangan. Bekatul memiliki kandungan selulosa sebesar 8.7-11.4\% dan hemiselulosa sebesar 9.6$12.8 \%$ (Azzmi 2012). Bekatul juga mengandung senyawa fitokimia yang dapat menurunkan kolesterol, seperti tanin, saponin, flavonoid, dan alkaloid (Moko et al. 2014). Angkak juga dapat menurunkan kolesterol. Angkak merupakan beras yang difermentasi oleh kapang Monascus purpureus. Hasil metabolit sekunder yang dihasilkan oleh kapang tersebut yaitu alkaloid, tanin, dan saponin (Hamid 2016). Radikal bebas merupakan salah satu penyebab terjadinya hiperkolesterolemia. Radikal bebas dalam tubuh menimbulkan stres oksidatif. Park dan Kim (2011) menyatakan bahwa angkak berpotensi sebagai antioksidan, dengan aktivitas sebesar $78.2 \%$. Widarta et al. (2013) menyatakan bahwa aktivitas antioksidan ekstrak metanol bekatul sebesar 88.84\%.

Pemanfaatan bekatul dan angkak sebagai pangan olahan masih belum banyak dilakukan. Pembuatan pangan olahan dari bekatul dan angkak perlu dilakukan guna menurunkan prevalensi hiperkolesterolemia di Indonesia. Salah satu pangan olahan yang dapat diproduksi yaitu agar-agar. Agar-agar adalah cemilan yang digemari oleh masyarakat Indonesia dengan kadar serat yang cukup tinggi. Penelitian ini dilakukan untuk mengevaluasi besar penambahan serat pada produk agar-agar dengan penambahan bekatul dan angkak. Adanya metabolit sekunder berupa saponin, alkaloid, tanin, dan flavonoid memperkaya senyawa yang dapat mengikat kolesterol pada agar-agar. Kemampuan pengikatan kolesterol oleh bekatul dan angkak pada produk agar-agar belum dilakukan. Pengujian in vitro juga dilakukan untuk mengetahui pengikatan produk agar-agar bekatul angkak terhadap kolesterol.

\section{BAHAN DAN METODE}

\section{Bahan}

Bahan utama yang digunakan adalah angkak yang berasal dari pasar tradisional di Baranangsiang, Bogor dan bekatul yang diperoleh dari penggilingan padi di Dramaga, Bogor.

\section{Proses pembuatan produk agar-agar}

Produk agar-agar yang digunakan adalah agar-agar Swallow. Pembuatan produk agar-agar dilakukan dengan tahapan penyangraian bekatul selama 10 menit pada suhu $90^{\circ} \mathrm{C}$. Bekatul disaring menggunakan ayakan 125 mesh.
Angkak dihaluskan menggunakan blender kemudian dilakukan penyaringan. Sebanyak 0.8 gram angkak halus dimasukkan ke dalam 650 air yang telah dipanaskan. Penambahan sodium sitrat berbeda untuk ketiga formula agar-agar yaitu sebanyak $0.1,0.2$ dan $0.3 \%$ untuk sampel 1,2 dan 3 secara berurut. Sodium. Selanjutnya ditambahkan sukralosa, 60 gram gula pasir, 7 gram bubuk agar plain, dan 30 gram bekatul sangrai. Tiga formula agaragar ditunjukkan pada Tabel 1. Campuran dipanaskan sampai mendidih. Agar-agar dituangkan pada cetakan dan didiamkan sampai memadat.

Tabel 1. Tiga Formula produk agar-agar dengan penambahan angkak dan bekatul

\begin{tabular}{|c|c|c|}
\hline Sampel 1 & Sampel 2 & Sampel 3 \\
\hline Agar-agar 7 gram & Agar-agar 7 gram & Agar-agar 7 gram \\
\hline Angkak 0.8 gram & Angkak 0.8 gram & Angkak $0.8 \mathrm{gram}$ \\
\hline sitrat $0.1 \%$ & sitrat $0.3 \%$ & Sodium sitrat $0.2 \%$ \\
\hline Bekatul 30 gram & Bekatul 30 gram & gram \\
\hline Gula pasir 60 gram & Gula pasir 60 gram & Gula pasir $60 \mathrm{gram}$ \\
\hline Sukralosa-laktosa & Sukralosa-laktosa & Sukralosa-laktosa \\
\hline Air $650 \mathrm{~mL}$ & Air $650 \mathrm{~mL}$ & Air $650 \mathrm{~mL}$ \\
\hline Vanili & Vanili & Vanili \\
\hline Perisa jeruk & Perisa jeruk & Perisa jeruk \\
\hline
\end{tabular}

\section{Analisis proksimat}

Produk agar-agar yang dihasilkan dianalisis proksimatnya yang terdiri dari kadar air, abu, perotein dan lemak (SNI 01-2891-1992). Untuk kadar karbohidrat dilakukan dengan metode by difference.

\section{Kadar serat pangan (AOAC 1999)}

Analisis serat pangan dilakukan dengan metode enzimatik-gravimetri. Lemak, protein, dan pati dalam sampel dihilangkan terlebih dahulu melalui perlakuan enzimatis dengan menggunakan termamyl (amilase tahan panas) (Sigma, German), protease (Sigma, German), dan $\alpha$-4-amiloglukosidase (Sigma, German) untuk menghilangkan protein dan pati. Soluble dietary fiber (SDF) yang terlarut dalam larutan sampel yang telah mengalami perlakuan enzimatis diendapkan dengan penambahan etanol 9\% (Merck, German). Setelah dilakukan penyaringan, residu dicuci dengan etanol kembali.

\section{Kadar total fenolik (modifikasi Pourmorad et al. 2006)}

Analisis kandungan total fenolik menggunakan metode Folin-Ciocalteu (Pourmorad et al. 2006). Standar asam galat diukur absorbansinya pada panjang gelombang $765 \mathrm{~nm}$. Sebanyak 100-150 mg sampel ditambahkan $0.5 \mathrm{~mL}$ metanol, $2.5 \mathrm{~mL}$ akuades, dan $2.5 \mathrm{~mL}$ pereaksi Folin-Ciocalteau $50 \%$ (Merck, German). Campuran didiamkan selama 5 menit, ditambahkan dengan $2 \mathrm{~mL}$ $\mathrm{Na}_{2} \mathrm{CO}_{3} 7.5 \%$, dan divorteks lalu diinkubasi selama 15 menit pada suhu $45^{\circ} \mathrm{C}$. Absorbansi sampel diukur pada panjang gelombang $765 \mathrm{~nm}$ dengan menggunakan spektrofotometer UV-Vis (UVmini-1240 Shimidzu, Jepang).

\section{Kadar total flavonoid (BPOM 2004)}

Sampel ditimbang sebanyak 3 gram dan dimasukkan ke dalam labu takar. Sampel ditambahkan $1 \mathrm{~mL}$ larutan 
heksametilentetramina (HMT) $0.5 \%$ (Sigma, German), $20 \mathrm{~mL}$ aseton (Merck, German), dan $2 \mathrm{~mL}$ larutan $\mathrm{HCl}$ (Merck, German). Campuran dihidrolisis dengan cara direfluks selama 30 menit. Campuran disaring menggunakan kapas. Filtrat dimasukkan ke dalam labu ukur $100 \mathrm{~mL}$, ditambah dengan aseton sampai volume $100 \mathrm{~mL}$. Filtrat diambil sebanyak $20 \mathrm{~mL}$, dimasukkan ke dalam corong pisah, ditambah $20 \mathrm{~mL}$ air, dan diekstraksi sebanyak tiga kali masing-masing dengan $15 \mathrm{~mL}$ etil asetat (Merck, German). Fraksi etil asetat dikumpulkan dan ditambah dengan etil asetat sampai volume mencapai $50 \mathrm{~mL}$. Sebanyak $10 \mathrm{~mL}$ campuran tersebut dimasukkan ke dalam labu ukur $25 \mathrm{~mL}$, ditambahkan dengan $\mathrm{AlCl}_{3}$ 10\% (Merck, German) sampai tanda tera dan dilarutkan dengan asam asetat glasial. Campuran divorteks dan dibaca nilai absorbansinya pada panjang gelombang $370.8 \mathrm{~nm}$ menggunakan spektrofotometer UV-Vis (BPOM 2004).

\section{Pengujian in vitro pengikatan kolesterol (Das et al. 2015)}

Pengukuran pengikatan kolesterol dilakukan dengan metode Lieberman Burchard. Metode ini sering digunakan untuk mengukur total kolesterol dan fitokimia jenis steroid dalam tanaman. Pengujian pengikatan kolesterol berdasarkan Das et al. 2015 dengan modifikasi. Produk agar-agar telah dilakukan pengeringan menggunakan oven vakum (Lindberg/Blue). Sebanyak 0.5 gram agaragar kering dilarutkan dengan kloroform hingga konsentrasinya menjadi $1000 \mathrm{ppm}$. Sebanyak $4 \mathrm{~mL}$ larutan dipindahkan ke dalam tabung reaksi bertutup, ditambahkan $1 \mathrm{~mL}$ larutan stok kolesterol 1000 ppm, dihomogenasikan dengan vortex, dan didiamkan pada ruang gelap selama 30 menit. Selanjutnya masing-masing ditambahkan asam asetat anhidrat sebanyak $2 \mathrm{~mL}$ dan $0.1 \mathrm{~mL}$ $\mathrm{H}_{2} \mathrm{SO}_{4}$, dihomogenasikan dengan vortex, didiamkan selama 15 menit di ruang, gelap dan diukur absorbansinya dengan menggunakan panjang gelombang maksimum. Kloroform sebanyak $5 \mathrm{~mL}$ digunakan sebagai blanko.

\section{HASIL DAN PEMBAHASAN}

\section{Komposisi kimia produk agar-agar}

Analisis proksimat dilakukan untuk mengetahui komposisi kimia yang terdapat pada produk agar-agar dengan penambahan bekatul dan angkak. Tabulasi formula produk agar-agar ditunjukkan pada Tabel 2, sedangkan hasil analisis proksimat ditunjukkan pada Tabel 3. Hasil analisis menunjukkan bahwa kadar karbohidrat produk agar-agar sangat tinggi, yaitu sebesar 19.97\%. Karbohidrat dapat dikelompokkan menjadi karbohidrat yang dapat dicerna dan karbohidrat yang tidak dapat dicerna. Karbohidrat yang tidak dapat dicerna terdiri atas serat yang dapat larut (SDF) dan serat yang tidak dapat larut (IDF). Menurut Azzmi (2012), bekatul memiliki kandungan serat yaitu berupa selulosa sebesar 8.7-11.4\% dan hemiselulosa sebesar 9.6-12.8\%, sedangkan angkak mengandung serat pangan sebesar 0.38\% (Abdillah 2013).
Tabel 2. Formula produk agar-agar formula terpilih

\begin{tabular}{lcc}
\hline \multicolumn{1}{c}{ Sampel } & (Gram) & (\% Per Total Berat Produk) \\
\hline Bubuk agar-agar & 7.00 & 0.93 \\
Serbuk angkak & 0.80 & 0.11 \\
Bekatul sangrai & 30.00 & 3.99 \\
Sodium sitrat & 2.25 & 0.30 \\
Gula pasir & 60.00 & 7.98 \\
Sukralosa-laktosa & 1.00 & 0.13 \\
Air & 650.00 & 86.43 \\
Vanili & 1.00 & 0.13 \\
\hline Total & 752.05 & 100 \\
\hline
\end{tabular}

Tabel 3. Analisis proksimat produk agar-agar formula terpilih

\begin{tabular}{cc} 
Komposisi Kimia & $(\%$ bb) \pm SD \\
\hline Lemak & $0.20 \pm 0.007$ \\
Protein & $0.42 \pm 0.010$ \\
Abu & $0.54 \pm 0.007$ \\
Air & $78.87 \pm 0.020$ \\
Karbohidrat & $19.97 \pm 0.040$
\end{tabular}

Keterangan: bb merupakan basis basah

Tingginya kadar karbohidrat pada produk dapat berasal dari karbohidrat yang dapat dicerna berupa sukrosa dan karbohidrat yang tidak dapat dicerna berupa IDF dan SDF. IDF dan SDF dapat berasal dari bubuk agar-agar. serbuk angkak. dan bekatul yang digunakan pada penelitian. Bubuk agar-agar mengandung serat pangan sebesar $5.88 \%$. angkak sebesar $0.38 \%$ (Abdillah 2013). dan bekatul sebesar $8.80 \%$. Data kadar serat pangan dapat dilihat pada Tabel 4. Produk agar-agar mengandung lemak sebesar $0.20 \%$. Lemak pada produk diperoleh dari bekatul dan bubuk agar-agar yang digunakan. Bekatul mengandung lemak sebesar 10-23\%. sedangkan pada bubuk agar-agar sebesar $0.10 \%$ (Ardiansyah 2008).

Tabel 4. Nilai TDF sampel menggunakan metode AOAC \begin{tabular}{lc}
\multicolumn{1}{c}{$(1999)$} & Sampel \\
\hline Angkak & $5.88^{*}$ \\
Bekatul & 8.80 \\
Produk agar-agar & 14.80 \\
\hline Keterangan: *penelitian dilakukan oleh Nurjanah et.al 2007
\end{tabular}

Kandungan air pada produk agar-agar cukup tinggi. yaitu $78.87 \%$. Hal tersebut menyebabkan singkatnya masa simpan produk. Produk agar-agar mulai mengalami kerusakan setelah disimpan selama tujuh hari pada refrigerator. Tanda-tanda kerusakan yang timbul diantaranya terjadi pemisahan air pada produk. timbulnya bau menyimpang. serta adanya lendir dan jamur pada permukaan produk. Kerusakan yang sama terjadi di hari ketujuh pada agar-agar tanpa penambahan bekatul dan angkak. Hal tersebut menunjukkan bahwa penambahan bekatul dan angkak tidak mempengaruhi masa simpan agar-agar. Takaran saji yang digunakan untuk produk agar-agar sebesar 30 gram. sesuai dengan takaran saji pada produk komersial sejenis. Produk agar-agar mengandung total lemak sebesar 0.06 gram. protein 0.13 gram. air 23.66 gram. dan karbohidrat sebesar 5.99 gram. Produk agar-agar memenuhi nilai AKG untuk karbohidrat sebesar $1.85 \%$. Kebutuhan harian karbohidrat mengacu pada BPOM (2016). yaitu sebesar 323 gram. Lemak dan protein pada produk agar-agar kurang dari 0.5 
gram per sajian. oleh karena itu bukan merupakan sumber lemak dan protein.

\section{Serat pangan}

Kadar total serat pangan (TDF) agar-agar dengan penambahan bekatul dan angkak dilakukan pada formula yang paling disukai berdasarkan pengujian rating hedonik. yaitu dengan penambahan konsentrasi sodium sitrat sebesar 0.3\%. Menurut BPOM (2016). pangan dapat dikatakan sebagai pangan tinggi serat apabila mengandung serat minimal sebesar $6 \%$. Serat pangan yang terkandung pada agar-agar yang digunakan dalam penelitian untuk membuat produk agar-agar sebesar 5.88\% (Nurjanah et al. 2007). Pengujian serat pangan pada bekatul juga dilakukan pada penelitian. Hal tersebut dilakukan untuk mengetahui besarnya serat pangan awal bekatul yang digunakan pada produk agar-agar. Serat pangan pada bekatul diperoleh sebesar $8.80 \%$ (Tabel 3). Data menunjukkan bahwa penambahan bekatul dan angkak menambahkan nilai serat pangan pada agar-agar. Bekatul dan angkak menambahkan nilai serat pangan pada agar-agar sekitar $8 . .92 \%$.

\section{Total fenolik dan flavonoid}

Tidak terdeteksi senyawa fenol pada penelitan ini. Absorbansi yang dihasilkan tidak masuk dalam rentang kurva standar. Larutan standar dibuat menggunakan asam galat dengan variasi konsentrasi 0. 20. 40. 60. dan 80 ppm. Pada produk agar-agar. ion fenolat yang mereduksi asam heteropoli (fosfomolibdat-fosfotungstat) menjadi kompleks molibdenum-tungsten pada produk agar-agar sangat sedikit sehingga warna biru yang dihasilkan yaitu biru muda sedikit pudar. Absorbansi dari warna yang dihasilkan tersebut jauh lebih rendah dibandingkan dengan warna yang dihasilkan pada standar asam galat.

Penentuan total flavonid dilakukan dengan metode pewarnaan $\mathrm{AlCl}_{3}$. Hasil positif ditandai dengan pembentukan kompleks antara $\mathrm{AlCl}_{3}$ dengan gugus keto pada atom $\mathrm{C}-4$ dan juga dengan gugus hidroksi pada atom C-3 atau C-4 menghasilkan warna kuning. Hasil pengukuran total flavonoid menunjukkan bahwa pada produk agaragar mengandung total flavonoid sebesar $0.02 \%(\mathrm{~b} / \mathrm{b})$.

Wanti (2008) menyatakan bahwa angkak mengandung flavonoid kelompok antosianin. Walaupun antosianin memiliki struktur yang berbeda dengan flavon dan flavonol. antosianin memiliki kemungkinan terdeteksi dalam analisis. Antosianin memiliki struktur yang polar sehingga mudah larut dalam pelarut yang polar dan semi polar (Wallace dan Gisuti 2014). sedangkan Ghasemzadeh et al. (2015) mengungkapkan bahwa ekstrak bekatul mengandung senyawa flavonoid berupa apigenin dari kelompok flavon. rutin dan kuersetin dari kelompok flavonol. serta katekin.

\section{Pengikatan kolesterol secara in vitro}

Hasil screening panjang gelombang maksimum untuk uji in vitro pengikatan kolesterol dengan menggunakan metode Lieberman-Burchard adalah $622.5 \mathrm{~nm}$ (Briliantama 2017). Hasil didapatkan dari hasil screening dengan spektrometer UV-Vis. ditandai dengan munculnya peak maksimum pada grafik. Terdapat kontrol positif dan kontrol negatif pada pengujian. Kontrol positif pada uji dilakukan untuk mengetahui konsentrasi kolesterol murni. Kontrol negatif diberikan untuk menghindari kesalahan positif akibat senyawa pada ekstrak yang dapat berubah menjadi warna hijau selama pengujian. Perubahan warna yang terjadi yaitu dari larutan tidak berwarna menjadi merah dan berubah dengan cepat menjadi warna biru violet (kolekalsiterol kolesterol). Warna biru tersebut akan berubah menjadi warna hijau (ergokalsiferol). Kontrol positif yang digunakan yaitu kolesterol yang dilarutkan dalam kloroform dari larutan stok. Kolesterol tidak dapat larut dalam air namun larut dalam pelarut nonpolar seperti kloroform. sehingga kloroform digunakan sebagai pelarut dan juga merupakan pelarut dalam metode Liebermann Burchad. Sementara. kontrol negatif yaitu hanya terdiri dari sampel produk agar-agar.

Produk agar-agar dengan penambahan bekatul dan angkak dapat mengikat kolesterol. Hal ini ditunjukkan oleh penurunan absorbansi sampel dibandingkan dengan kontrol positif. yang menandakan bahwa semakin banyak kolesterol yang terikat oleh ekstrak kloroform produk agar-agar dengan penambahan bekatul dan angkak. Besar pengikatan kolesterol oleh produk agar-agar dengan penambahan bekatul dan angkak sebesar $60.11 \pm 0.9 \%$ berdasarkan basis kering atau $13.24 \%$ untuk basis basah. Sementara. kefir susu sapi dapat menurunkan kolesterol sebesar 31.45\% (Wahdania dan Pramono. 2012). sedangkan Widyaningsih dan Dhesti (2014) melaporakan pengikatan kolesterol oleh liang teh cincau sebesar $52.81 \%$ secara in vivo.

Pengikatan kolesterol ekstrak angkak dan bekatul diduga karena adanya senyawa metabolit sekunder seperti flavonoid. saponin. alkaloid dan tanin. Adanya komponen metabolit sekunder tersebut dapat merubah stuktur kimia kolesterol atau terjadi pengendapan kolesterol karena senyawa saponin dapat dapat membentuk kompleks misel yang besar dengan kolesterol dan misel tersebut memiliki berat molekul yang besar sehingga mengendap (Matsui et al. 2009). Selain itu tanin juga dapat mengikat lipid sehingga dapat mengurangi kolesterol yang terukur.

Berdasarkan hasil penelitian Hasim et al. (2018). campuran fraksi air ekstrak angkak dan bekatul dengan rasio 1:3 memiliki potensi sebagai pangan fungsional antihiperkolesterolemia dengan mekanisme penghambatan HMG KoA reduktase (51.85\%). Gunasekaran et al. (2015) penghambatan enzim HMG KoA reduktase dapat menurunkan kolesterol pada manusia dan hewan. Enzim tersebut dapat mengkalisis konversi HMG KoA menjadi asam mevalonat yang merupakan proses vital dari biosentesis kolesterol dalam tubuh.

Pada bekatul terdapat senyawa $\gamma$-oryzanol. salah satu jenis stanol yang memiliki kemampuan untuk menurunkan kolesterol. Wheeler dan Garleb 1991 melaporkan bahwa $\gamma$-oryzanol memiliki struktur yang mirip dengan kolesterol. senyawa tersebut berkompetisi selama proses 
penyerapan kolesterol sehingga dapat menghambat proses penyerapan kolesterol. Sementara pada angkak terdapat senyawa monacalin K. suatu metabolit sekunder yang secara kimia identik dengan lovastatin dan memiliki kemampuan menurunkan kolesterol (Zhang et al. 2016).

\section{KESIMPULAN}

Produk agar-agar dengan penambahan angkak dan bekatul dapat mengikat kolesterol sebesar $60.11 \pm 0.9 \%$ (bk) atau $13.24 \%$ (bb) secara in vitro lebih tinggi dibandingkan dengan produk komersial yang dapat mengklaim pengikatannya sebesar $10 \%$. Pengikatan kolesterol ekstrak angkak dan bekatul diduga karena adanya senyawa metabolit sekunder seperti flavonoid. saponin. alkaloid dan tanin. Adanya komponen metabolit sekunder tersebut dapat merubah stuktur kimia kolesterol atau terjadi pengendapan kolesterol.

\section{UCAPAN TERIMA KASIH}

Ucapan terima kasih disampaikan kepada Fata Muslim Fikri. Febi Putri Fitriani dan Ika Faztin Cahyanti yang telah membantu dalam pelaksanaan penelitian ini. Penelitian ini didanai melalui program penelitian strategis aplikasi (PSA) tahun 2017 dari KEMENRISTEK DIKTI.

\section{DAFTAR PUSTAKA}

Abdillah F. 2013. Studi Awal Pengaruh Variasi Konsentrasi Starter Monascus purpureus Terhadap Kadar Lovastatin dalam Angkak Sagu. Malang (ID): Akademi Analisis Farmasi dan Makanan Putra Indonesia.

Al-Numair KS, Chandramohan, G, Alsaif MA, Veeramani C, El Newehy AS. 2014. Morin, a flavonoid, on lipid peroxidation and antioxidant status in experimental myocardial ischemic rats. Aft $\mathrm{J}$ Tradit Complement Altern Med 11(3): 14-20.

[AOAC] Assosiation of Official Analytical Chemist. 1999. Official Method of Analysis. AOAC International. Washington DC.

Ardiansyah. 2008. Bekatul untuk Menurunkan Hipertensi dan Hiperlipidemia. Jakarta (ID): Gramedia Pustaka Utama.

Azzmi MU. 2012. Pembuatan Mi Bekatul Beras Merah Substitusi Tepung Ubi Jalar Ungu (Ipomoea babatas blackie) Kaya Antioksidan. [Skripsi]. Solo: Fakultas Pertanian. Universitas Sebelas Maret.

[BPOM] Badan Pengawas Obat dan Makanan. 2004. Monografi Ekstrak Tumbuhan Obat Indonesia. Volume 1. Jakarta.

[BPOM] Badan Pengawas Obat dan Makanan. 2016. Pengawasan Klaim pada Label dan Iklan Pangan Olahan. Jakarta.
Bottger S, Melzig MF. 2013. Pengaruh saponin pada kolesterol membran sel. Kimia Bioorganik dan Obat. Bioorganic Med Chem 21(22): 7118-7124. DOI: 10.1016/j.bmc.2013.09.008.

Briliantama A 2017. Pengikatan Kolesterol In Vitro pada Ekstrak Angkak dan Bekatul Serta Pemanfaatannya sebagai Minuman Fungsional Serbuk Instan. [Skripsi]. Bogor: Fakultas Teknologi Pertanian. Institut Pertanian Bogor.

Dalimartha S. 2005. Ramuan Tradisional untuk Pengobatan Diabetes Mellitus. Penebar Swadaya. Bogor.

Das M, Malipeddi H, Nambiraj NA, Rajan R. 2015. Phytochemical analysis. antioxidant activity and in vitro growth inhibition of struvite crystals by ipomoea eriocarpa leaf extracts. J Food Biochem 40: 148-160. DOI: 10.1111/jfbc.12205.

Hamid AW. 2016. Aktivitas Antioksidan Hasil Fraksinasi Ekstrak Etanol Angkak dan Bekatul dengan Metode Reduksi Ferri (FRAP). [Skripsi]. Bogor: Fakultas Matematika dan Ilmu Pengetahuan Alam. Institut Pertanian Bogor.

Hasim, Hasanah Q, Andrianto D, Faridah DN. 2018. Aktivitas antioksidan dan antihiperlipideamia in vitro dari campuran ekstrak angkak dan bekatul. J Teknoln Industri Pangan 29(2): 145-154. DOI: 10.1066/jtip. 2018.2.145.

Ghasemzadeh A, Jaafar HZE, Juraimi AS, TayebiMeigooni A. 2015. Comparative evaluation of different extraction techniques and solvent for the assay of phytochemicals and antioxidant activity of hashemi rice bran. Molecules 20: 10822-10838. DOI: 10.3390/molecules200610822.

Gunasekaran B, Salvamani S, Azlan A, Ahmad SA, Yeap SK, Shukor MY. 2015. Hypocholesterolemic and antiatherosclerotic potential of Basella alba leaf extract in hypercholesterolemia-induced rabbits. Evidence-based Complementary Altern Med 2: 1-7.

Mahan LK, Escott-Stump S. 2008. Krause's Food and Nutrition Therapy 12th edition. Saunders Elsevier. Philadelphia.

Matsui Y, Kobayashi K, Musada H, Kigoshi H, Akao M, Sakurai H. 2009. Quantitative Analysis of saponins in a tea-leaf extract and their antihypercholesterolimic activity. Biosci Biotechnol Biochem 73(7): 153-1519. DOI: 10.1271/bbb.90003.

Moko EM, Purnomo HKJ, Ijong FG. 2014. Phytochemical content and antioxidant properties of colored and non colored varieties of rice bran from Minahasa. North Sulawesi. Indonesia. Int Food Res J 21: 1053-1059.

Nurjanah, Pipih S, Lila R. 2007. Pembuatan tepung puding instan karaginan. Bul Teknologi Hasil Perikanan 10(1): 59-69.

Park HJ, Kim IS. 2011. Antioxidant activities and anticancer effect of red yeast rice grown in the medium containing garlic. Food Sci Biotech 20: 297302. DOI: $10.1007 / \mathrm{s} 10068-011-0042-5$. 
Pourmorad F, Hossenimehr SJ, Shahabimajd N. 2006. Antioxidant activity. phenol and flavonoid contents of some selected Iranian medicial plants. African J Biotech 5: 1142-1145.

Ramirez-Jimenez AK, Reynoso-Camacho R, Tejero ME, Leon-Galvan F, Loarca-Pina G. 2015. Potential role of bioactive compounds of Phaseolus vulgaris L. on lipids-lowering mechanisms. Food Res Int 76(1): 92104. DOI: 10.1016/j.foodres.2015.01.002.

[Riskesdas]. Riset Kesehatan Dasar. 2013. Balai Penelitian dan Pengembangan Kesehatan Kementerian Kesehatan RI. Riskesdas. Jakarta.

Wallace TC, Giusti MM. 2014. Anthocyanins in Health and Disease. CRC Press. Boca Raton. DOI: 10.1201/b15554.

Wanti S. 2008. Pengaruh Berbagai Jenis Beras terhadap Aktivitas Antioksidan pada Angkak oleh Monascus purpureous. [Skripsi]. Solo: Universitas Sebelas Maret.

Wahdania F, Pramono A. 2012. Pengaruh pemberian kefir susu sapi terhadap kadar kolesterol total tikus jantan sprague dawley. J Nutr College (UNDIP). 1(1): 224-228.

Wheeler KB, Garleb KA. 1991. Gamma orizanol-plant sterol supplementation: metabolic. endocrine and physiologic effect. International J Sport Nutr 1: 170177. DOI: 10.1123/ijsn.1.2.170.

Widarta IWR, Nocianitri KA, Sari LPIP. 2013. Ekstraksi komponen bioaktif bekatul beras lokal dengan beberapa jenis pelarut. J Aplikasi Teknol Pangan 2: 75-79.

Widyaningsih TD, Dhesti AP. 2014. Pengaruh pemberian liang teh cincau hitam (Mesona palustris BL) terhadap kadar kolesterol tikus wistar. J Pangan dan Agroindustri 2(2): 103-109

Zhang Z, Ali Z, Khan SI, Khan IA. 2016. Cytotoxic monacolins from red yeast rice. a Chinese medicine and food. Food Chem 202: 262-268. DOI: 10.1016/j.foodchem.2015.12.039.

JMP-03-19-02-Naskah diterima untuk ditelaah pada 11 Maret 2019. Revisi makalah disetujui untuk dipublikasi pada 24 Oktober 2019. Versi Online: http://journal.ipb.ac.id/index.php/jmpi 